\title{
Spaeth G L, Danesh-Meyer H, Goldberg I, Kampik A (2012) Ophthalmic Surgery-Principles and Practice, 4th edition. Saunders, Philadelphia: ISBN 978-1-4377-2250-5
}

\author{
Shimon Rumelt \\ Received: 25 September 2012 / Accepted: 15 October 2012 /Published online: 20 December 2012 \\ (C) Springer-Verlag Berlin Heidelberg 2012
}

\begin{abstract}
Almost every ophthalmologist wishes to master surgical techniques. This book is intended to assist surgeons to achieve their mission. Of course, as all surgical specialties, surgery is an apprentice profession, much depending on study from others and from the surgeon's own experience, but any book, as any talk or presentation, adds small tips that make a huge difference to the outcome.

This is the 4th edition of the book, which is intended for practitioners and trainees. It is composed of nine sections that cover the different subspecialties in ophthalmology. The different topics are covered by prominent authors, each in his/hers own specialty. Most of the participants are from the United States. Each chapter usually starts with a general description or surgical principles, followed by a more detailed description of the indications, procedures, and intraand postoperative complications. The outcomes and prognosis are less addressed. However, the book is not prepared as a "cookbook", and therefore does not describe each procedure step by step. The video clips demonstrate the procedures more as a step-by-step approach. These video clips are accessible online through the "Expert Consult" approach, which allows free online access to the full text and the video clips. The video clips are very explanatory, and contain clinical videos as well as some schematic ones in the cataract section and of each step of the procedures in a consecutive manner. The video clips are an essential part of the book, and are an excellent supplement for the trainee.
\end{abstract}

However, they do not include all the common procedures that are the armamentarium of each subspecialist such as glaucoma shunt tube insertion and newer implant insertion. The videos reflect the surgeon's own perspective, and this may vary from one subspecialist to the other. Each book contains numerous illustrations, diagrams, and color images. The references in some chapters are, however, succinct. The publisher, Elsevier, has published the finest and most elegant book on glossy paper with high-color photographs.

The book contains most of the classic as well as the novel procedures such as the different anterior and posterior corneal lamellar surgeries [including laser in-situ keratomileusis (LASIK), epithelial assisted in-situ keratomileusis, epilas etc.]. Some of the newer topics are briefly mentioned, for example multifocal and accommodative intraocular lenses, while only a few topics are absent, including femtosecond laser for cataract surgery, eyelid-corneal keratoprosthesis and brow-lift techniques (including endoscopic).

In summary, this is an excellent companion to every ophthalmic surgeon, in which he/she can find interesting tips to master surgery and be updated in subspecialties other than his. It is hoped that more editions will follow this one, and will include new innovations to encompass the whole field of ophthalmology, with inclusion of more video clips. Hopefully, the reader will have indefinite access to the online version of the book.

\footnotetext{
S. Rumelt $(\bowtie)$

Ophthalmology Department, Western Galilee Medical Center,

P O Box 21, Nahariya 22100, Israel

e-mail: shimon.rumelt@naharia.health.gov.il
} 